\title{
Cloning, Expression, Purification and Oligomeric Characterization of the AopB-C-terminus Domain in T3SS Major Translocator Protein of Aeromonas hydrophila
}

\author{
Nguyen Van Sang*, Nguyen Thi Uyen \\ VNU University of Science, 334 Nguyen Trai, Thanh Xuan, Hanoi, Vietnam \\ Received 06 August 2021 \\ Revised 20 August 2021; Accepted 25 August 2021
}

\begin{abstract}
Type three secretion system (T3SS) is found exclusively in gram-negative pathogens such as Yersinia spp., Escherichia coli, Salmonella spp., Shigella spp., Pseudomonas spp., Vibrio parahaemolyticus, and Aeromonas hydrophila. The translocon pore of T3SS comprises major and minor translocator proteins that assemble to provide passage of effectors through the host cell membrane. Major translocator protein AopB from Aeromonas hydrophila plays an important role in translocon pore formation. Despite tremendous efforts, structural information regarding the C-terminus domain of major translocator AopB remains elusive. In this study, the DNA fragment encoding for the $\mathrm{C}$-terminus domain of the AopB from Aeromonas hydrophila AH-1 was cloned into pET-M expression vector and expressed in Escherichia coli BL21 (DE3) host cells. The recombinant AopB-C-terminus domain was successfully purified using immobilized nickel affinity chromatography as a soluble form. Crosslinking analysis among AopB-C-terminus molecules in solution showed that this domain existed as a mixture of tetramer, trimer, dimer, and monomer forms. The three-dimensional structure model of AopB-C-terminus oligomerization was built by SWISS-MODEL and PyMol. The oligomeric model of AopB-C-terminus can be used for structural studies of the AopB-C-terminus domain, which can contribute to the elucidation of the structure of the type III secretion system.
\end{abstract}

Keywords: Aeromonas hydrophila, affinity chromatography, AopB-C-terminus domain, gene expression, oligomerization.

\section{Introduction}

Aeromonas hydrophila is a gram-negative bacterium that causes disease in many organisms such as fish, shrimp, and humans

\footnotetext{
"Corresponding author.

E-mail address: nvsangvnu@yahoo.com

https://doi.org/10.25073/2588-1140/vnunst.5293
}

leading to mass death in fish in aquaculture farms. Similar to other gram-negative bacteria, Aeromonas hydrophila uses a type three secretion system (T3SS) to deliver toxins into the host [1, 2]. T3SS consists of complex macromolecular machinery, translocator and effector proteins, chaperone, and other accessory proteins [3]. In T3SSs, the translocator proteins 
play an important role in the pore formation on the host cell membrane and help bacterial toxins to enter the host $[1,4]$. Many translocators of bacterial families have been identified such as AopB/AopD (Aeromonas sp.), IpaB/IpaC (Shigella spp.), YopB/YopD (Yersinia spp.), PopB/PopD (Pseudomonas spp.), and $\mathrm{SipB} / \mathrm{SipD}$ (Salmonella spp.) [2].

To date, structure information of major translocators is limited to a short $\mathrm{N}$-terminal peptide (9-13 residues) [5-8] of translocator PopB with chaperon PcrH in 2012 [9], the structure of $\mathrm{IpaB} / \mathrm{IpgC}$ [10], or IpaD [11]. Especially, in 2015 Nguyen et al. showed the structure of the N-terminal parts of the translocator AopB (1-264) with its chaperon AcrH [12]. Currently, there is no structural information available to show how the C-terminus domain of major translocators interacts with other translocators. Here, we cloned the AopB-C-terminus domain (residue from 265 to 347) into a pET-M expression vector. The recombinant protein was expressed in E. coli BL21 (DE3) cell and purified by nickel affinity chromatography. We showed that AopB used the C-terminus domain to interact and form oligomeric stages which are necessary for functional T3SS formation.

\section{Materials and Methods}

The pET-DUET-1 AcrH-AopB vector, the pET-M expression vector, the E. coli DH5 , and the E. coli BL21 (DE3) were from the Molecular Cell Biology lab, in the Center of Life Science, Faculty of Biology, and VNU University of Science. Chemicals used in this experiment were bought from international companies as Bio-rad, Sigma, Merck, Thermo Fisher Scientific (United States), Bio Basic (Canada), or Serva (Germany).

\subsection{Cloning of AopB-C-terminus into pET-M Expression Vector}

A gene encoding for the AopB-C-terminus from amino acid 265 to amino acid 347 was amplified by polymerase chain reaction using forward primer AopB265-347-F (5'-GCggatccGTAGTTGATATTGGTACCGGGA-3') containing a sequence for BamHI cleavage and reverse primer AopB265-347-R (5'-CGgaattcTTAAATGGCTGTCGGTCTGC-3') containing a sequence recognized by EcoRI (Table 1). The DNA template was the pET-DUET-1 AcrH-AopB vector containing the full-length sequence of AopB. The PCR reaction used Phusion High-Fidelity DNA Polymerase (Thermo Scientific) with composition and the temperature cycle according to the guideline of the manufacturer.

The PCR product of the AopB-C-terminus gene and pET-M were digested by Fast Digest EcoRI and BamHI (Thermo Scientific). The DNA was inserted into the vector by T4 DNA ligase (Thermo Scientific). The ligated product was transformed into E. coli DH5 $\alpha$ competent cells then spread on LB agar medium added with ampicillin $(100 \mu \mathrm{g} / \mathrm{ml})$. The plasmid containing the AopB-C-terminus gene was screened by PCR screening method. Subsequently, plasmids are extracted from E. coli cells using GeneJET Plasmid Miniprep Kit (Thermo Scientific). The foreign gene in the selected plasmid was sequenced at $1^{\text {st }}$ Base (Singapore) using the Sanger method.

\subsection{Expression of AopB-C-terminus Protein}

The pET-M-AopB-C-terminus vector was transformed into $E$. coli BL21 (DE3). A single colony of transformant was cultured in $5 \mathrm{ml}$ LB containing $100 \mu \mathrm{g} / \mathrm{ml}$ of ampicillin (LBA medium) overnight, at $37{ }^{\circ} \mathrm{C}, 150 \mathrm{rpm}$. The overnight culture was transferred into $1 \mathrm{~L}$ of LBA and shaken at $37{ }^{\circ} \mathrm{C}$ until $\mathrm{OD}_{600}$ reached 0.6. The transcription of the foreign genes was initiated by adding $0.3 \mathrm{mM}$ IPTG (isopropyl $\beta$-D-1-thiogalactopyranoside) into the medium and continued culture at $25{ }^{\circ} \mathrm{C}$, $150 \mathrm{rpm}$ for 16 hours. The cells were collected by centrifugation for $10 \mathrm{~min}$ at $4000 \mathrm{rpm}$ and stored at $-30{ }^{\circ} \mathrm{C}$ until purification. 


\subsection{Purification of AopB-C-terminus}

The cell pellet was resuspended in $25 \mathrm{ml}$ of lysis buffer (Tris- $\mathrm{HCl} 30 \mathrm{mM}, \mathrm{pH} 8.0 ; \mathrm{NaCl}$ $300 \mathrm{mM}$; imidazole $5 \mathrm{mM}$ ) and were lysed by sonication on ice with $40 \%$ amplitude and for 6 rounds ( $3 \mathrm{~s}$ on, $3 \mathrm{~s}$ off) of $5 \mathrm{~min}$ each. The lysate was centrifuged at $13000 \mathrm{rpm}, 4{ }^{\circ} \mathrm{C}$ for $30 \mathrm{~min}$. The collected supernatant was loaded into Econo-column (Biorad) containing $3 \mathrm{ml}$ Ni-NTA bead pre-equilibrated with $20 \mathrm{ml}$ of lysis buffer. The nonspecific-binding proteins were removed from the column by washing step with washing buffer (Tris-HCl $30 \mathrm{mM}$, pH 8.0; $\mathrm{NaCl} 300 \mathrm{mM} ; 30 \mathrm{mM}$ imidazole). The AopB-C-terminus tagged hexahistidine was eluted with $20 \mathrm{ml}$ of elution buffer (Tris-HCl30 mM, pH 8.0; NaCl $300 \mathrm{mM}$; imidazole $500 \mathrm{mM}$ ). The eluted proteins were dialyzed overnight against phosphate-buffered saline buffer $(140 \mathrm{mM} \mathrm{NaCl}$, $2.7 \mathrm{mM} \mathrm{KCl}, 10 \mathrm{mM} \mathrm{Na} 2 \mathrm{HPO}_{4}$, and $1.8 \mathrm{mM}$ $\mathrm{KH}_{2} \mathrm{PO}_{4}, \mathrm{pH}$ 7.4) and stored at $-80{ }^{\circ} \mathrm{C}$.

\subsection{Chemical Crosslinking of AopB-C-terminus Domain}

The crosslinking reaction was conducted with $100 \mu \mathrm{L}$ of AopB-C-terminus $(1 \mathrm{mg} / \mathrm{mL}$ protein concentration) in PBS buffer and $0.2 \%$ glutaraldehyde. The reaction was carried out at $4{ }^{\circ} \mathrm{C}$ for 30 minutes. Total $20 \mu \mathrm{L}$ of the reaction mixture was sampled at $10 \mathrm{~min}, 20 \mathrm{~min}$, and

(A)

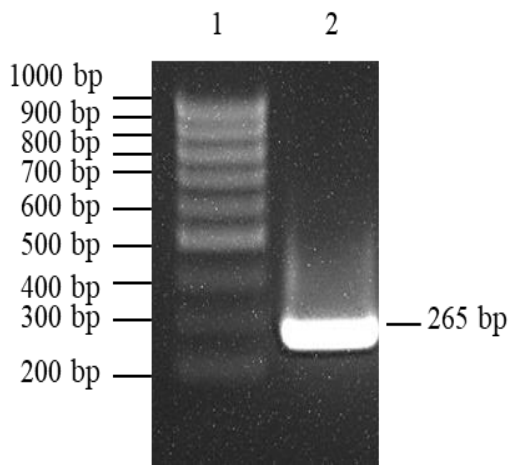

30 min periods. The samples were added with SDS loading dye buffer and denatured immediately at $95{ }^{\circ} \mathrm{C}$ for $5 \mathrm{~min}$. Then all samples were run on a $15 \%$ polyacrylamide gel SDS-PAGE.

\subsection{Modelling Oligomeric State of AopB-C-terminus}

The tertiary structure of AopB-C-terminus domain was modeled based on the amino acid sequence of this domain using SWISS-MODEL [13]. The oligomer structure was predicted based on the homologous structures published on PDB and analyzed by PyMOL software.

\section{Results and Discussion}

\subsection{Cloning of AopB-C-terminus Gene into the pET-M Expression Vector}

The AopB-C-terminus gene containing $B a m \mathrm{HI}$ and EcoRI restriction enzyme sites at 5' and 3' end, respectively, was amplified by Phusion DNA polymerase (Thermo Scientific). The result is shown in Figure 1(A). The AopB-C-terminus gene of 265 bp was specifically amplified by PCR (Lane 2, Figure $1 \mathrm{~A}$ ). The PCR product was digested by the BamHI and EcoRI and inserted into pET-M expression vector to generate a recombinant plasmid pET-M-AopB-C-terminus (Figure 1B).

The AopB-C-terminus gene in the recombinant vector was confirmed by Sanger sequencing.

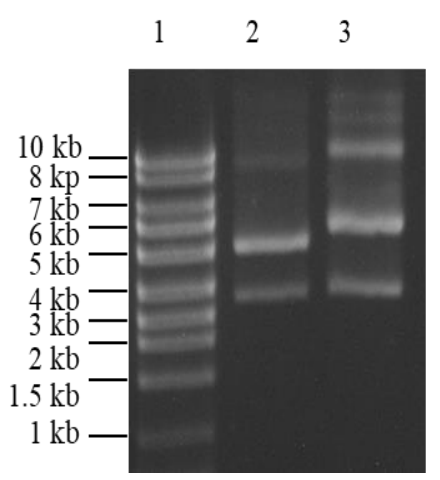

Figure 1. Analysis of PCR product of AopB-C-terminus gene (A) and extracted recombinant plasmid pET-M-AopB-C-terminus (B) by electrophoresis on agarose gel 0.8\%. 1A: DNA marker 100 bp (iNtRON); 2A: The PCR product. 1B: DNA marker $1 \mathrm{~kb}$ (iNtRON), 2B: Plasmid pET-M; 3B: pET-M-AopB-C-terminus. 


\subsection{Expression of AopB-C-terminus Domain in E. coli BL21 (DE3)}

The result of SDS-PAGE electrophoresis in Figure 2 shows that AopB-C-terminus domain with the length of $10.97 \mathrm{kDa}$ was expressed in E. coli BL21 (DE3) cells when the cells were cultured in the medium containing $0.3 \mathrm{mM}$ IPTG at $25^{\circ} \mathrm{C}$ (Lane 3, Figure 2) and this band was not observed in the control sample (Lane 2, Figure 2).

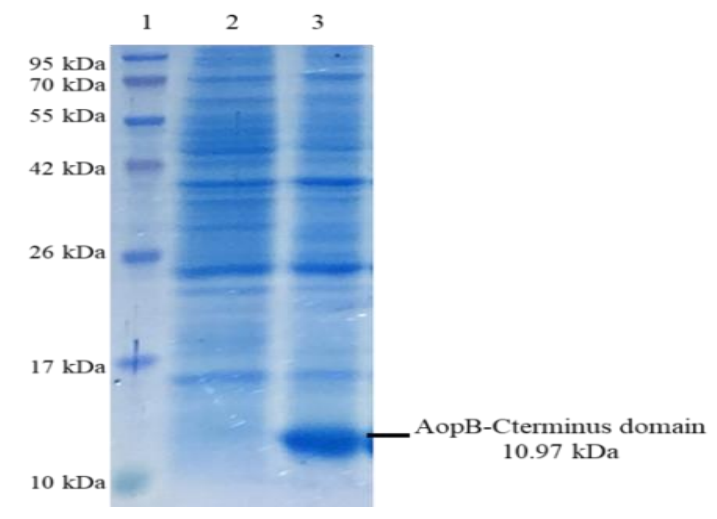

Figure 2. Analysis of total proteins

from E. coli BL21 harboring AopB-C terminus domain gene by SDS-PAGE.

1: Protein ladder (Lonza); 2: Proteins from the non-induced cells; 3: Proteins from the cells cultured in the presence of $0.3 \mathrm{mM}$ IPTG.

\subsection{Purification of His-tag AopB-C-terminus}

The protein AopB-C-terminus was purified using a Ni-NTA affinity column. The results (Figure 3) show that AopB-C-terminus domain was successfully purified with a thick specific band of about $10.97 \mathrm{kDa}$ in lane 7 . The AopB-C-terminus was dialyzed in PBS buffer overnight at $4{ }^{\circ} \mathrm{C}$. Dialyzed protein was aliquoted into $1 \mathrm{ml}$ tubes and stored at $-80{ }^{\circ} \mathrm{C}$ (Figure 3).

\subsection{Determination of Oligomeric States of the AopB-C-terminus}

In order to determine the oligomeric states of AopB-C-terminus, we performed chemical crosslinking between the AopB-C-terminus molecules in solution. Only the molecule closely interacts with each other would cross-link and result in higher molecular weight on denatured protein electrophoresis (SDS-PAGE) analysis. In Figure 4, lane 3, there are 4 bands with corresponding sizes for a dimer $(21.94 \mathrm{kDa})$, trimer $(32.91 \mathrm{kDa})$, and tetramer $(43.88 \mathrm{kDa})$ form of AopB-C-terminus domain.

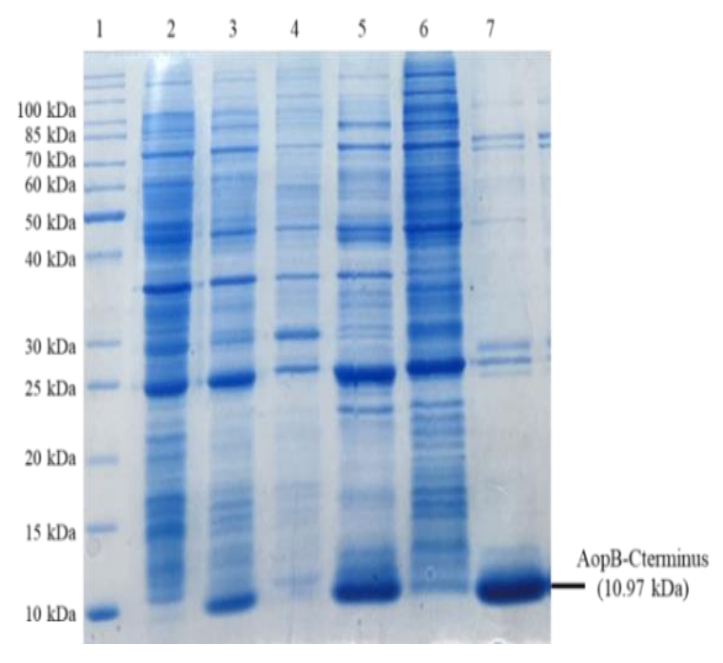

Figure 3. Analysis of protein fractions during AopB-C terminus-domain purification process by SDS-PAGE.

1: Protein ladder (Biobasic); 2: Proteins form non-induced cell; 3 : Protein from the cells cultured in the presence of IPTG; 4: Cell pellet;

5: Soluble proteins; 6: Flow-through from Ni-NTA affinity column; 7: Eluted protein from Ni-NTA column.

The results (Figure 4) indicate that a control protein sample, not incubated with chemical cross-link agent (glutaraldehyde), AopB-C-terminus domain existed at the monomer form of $10.97 \mathrm{kDa}$. After being treated with cross-link agent, AopB-C-terminus domain conformed polymer including tetramer, trimer, dimer and monomer forms. It also suggests that this domain responsible for oligomerization of AopB major translocator which can form tetramer in solution. This result demonstrates that the C-terminal region of AopB plays a role for molecule oligomerization that helps form the structure of this translocon in the translocation channel and the highest oligomeric state of AopB-C-terminus has at least 4 molecules linked together to form tetramers. 


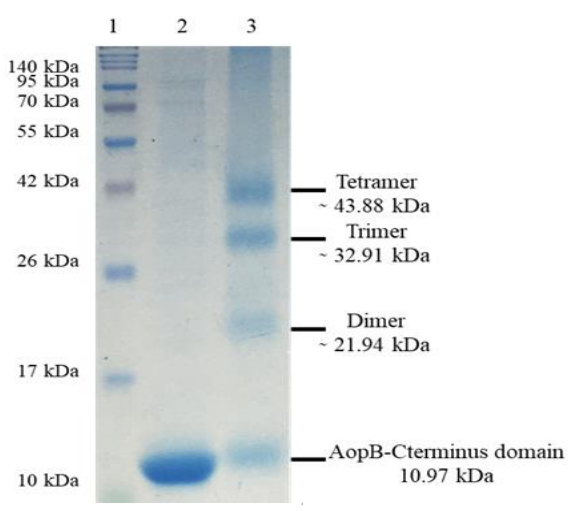

Figure 4. The result of chemical crosslinking reaction. Lane 1: Protein ladder (Lonza);

Lane 2: Monomeric AopB-C-terminus without chemical crosslink; Lane 3: crosslinked AopB-C-terminus domain.

\subsection{Oligomeric Model of AopB-C-terminus}

We modeled the three-dimensional structure of AopB-C-terminus using SWISS-MODEL software. The monomer and oligomer structure of the AopB-C-terminus domain was built based on a template with SWISS-MODEL Template Library ID (SMTL ID) of 105h.1.A. The result in Figure 5A shows the monomer form of AopB-C-terminus domain, mainly alpha helices.

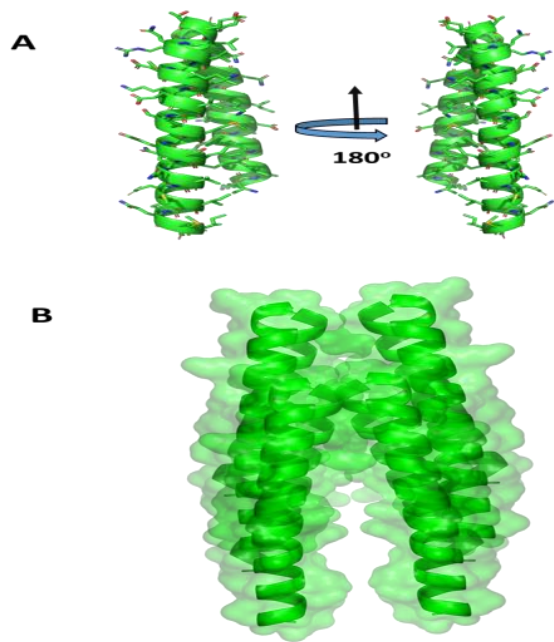

Figure 5. Structure models of AopB-C-terminus that were predicted by SWISS-MODEL.

(A): The monomeric structure model of AopB-C-terminus domain. (B): The oligomeric model of AopB-C-terminus domain based on chemical crosslink analysis.
The oligomer state of this protein was predicted based on the monomeric structure as well as the chemical crosslink analysis as shown in Figure 5B, which consists of parallel alpha-helices. Based on the published structure of the AopB N-terminal domain with the AcrH chaperon, we predict that the oligomerization of the $\mathrm{C}$-terminus helps align the $\mathrm{N}$-terminus region together to form the transmembrane region.

\section{Conclusion}

In this research, we cloned the AopB-C-terminus domain gene into the pET-M vector and induced the expression in E. coli BL21 (DE3). The AopB-C-terminus domain was purified by His-tag affinity chromatography. The highest oligomeric state of AopB-C-terminus domain could be at least tetramer form based on the result of the chemical crosslinking reaction. The structure models of AopB-C-terminus were predicted by SWISS-MODEL software. In the future, proteins with high purity can be used for further studies to understand their structure and function.

\section{Acknowledgements}

This research is funded by Vietnam National Foundation for Science and Technology Development (NAFOSTED) under grant number 106-NN.02-2016.58.

\section{References}

[1] S. Müller, M. F. Feldman, G. R. Cornelis, The Type III Secretion System of Gram-negative Bacteria: A Potential Therapeutic Target?, Expert Opinion on Therapeutic Targets, Vol. 5, 2001, pp. 327-339.

[2] P. Troisfontaines, G. R. Cornelis, Type III Secretion: more Systems than You Think, Physiology, Vol. 20, 2005, pp. 326-339.

[3] D. Büttner, U. Bonas, Port of Entry-the Type III Secretion Translocon, Trends in Microbiology, Vol. 10, 2020, pp. 186-192.

[4] B. J. Burkinshaw, N. C. Strynadka, Assembly and Structure of the T3SS, Biochimica et Biophysica Acta (BBA)-Molecular Cell Research, Vol. 1843, 2014, pp. 1649-1663. 
[5] K. F. A. Discola, A. Förster, F. Boulay, J. P. Simorre, I. Attree, A. Dessen, V. Job, Membrane and Chaperone Recognition by the Major Translocator Protein PopB of the Type III Secretion System of Pseudomonas Aeruginosa, Journal of Biological Chemistry, Vol. 289, 2014, pp. 3591-3601.

[6] V. Job, P. J. Matteï, D. Lemaire, I. Attree, A. Dessen, Structural Basis of Chaperone Recognition of Type III Secretion System Minor Translocator Proteins, Journal of Biological Chemistry, Vol. 285, 2010, pp. 23224-23232.

[7] M. Lunelli R. K. Lokareddy, A. Zychlinsky, M. Kolbe, IpaB-IpgC Interaction Defines Binding Motif for Type III Secretion Translocator, Proceedings of the National Academy of Sciences, Vol. 106, 2009, pp. 9661-9666.

[8] M. Schreiner, H. H. Niemann, Crystal Structure of the Yersinia Enterocolitica Type III Secretion Chaperone SycD in Complex with a Peptide of the Minor Translocator YopD, BMC Structural Biology, Vol. 12, 2012, pp. 1-9.

[9] S. Dey, A. Basu, S. Datta, Characterization of Molten Globule PopB in Absence and Presence of Its Chaperone PcrH, The Protein Journal, Vol. 31, 2012, pp. 401-416.
[10] M. L. Ferrari, S. N. Charova, P. J. Sansonetti, E. Mylonas, A. D. Gazi, Structural Insights of Shigella Translocator IpaB and Its Chaperone IpgC in Solution, Frontiers in Cellular and Infection Microbiology, 2021.

[11] A. D. Roehrich, E. Guillossou, A. J. Blocker, I. M. Argudo, S Higella IpaD has a Dual Role: Signal Transduction from the Type III Secretion System Needle Tip and Intracellular Secretion Regulation, Molecular Microbiology, Vol. 87, 2013, pp. 690-706.

[12] V. S. Nguyen, C. Jobichen, K. W. Tan, Y. W. Tan, S. L. Chan, K. Ramesh, Y. Yuan, Y. Hong, J. Seetharaman, K. Y. Leung, J. Sivaraman, Structure of AcrH-AopB Chaperone-translocator Complex Reveals a Role for Membrane Hairpins in Type III Secretion System Translocon Assembly, Structure, Vol. 23, 2015, pp. 2022-2031.

[13] F. Kiefer, K. Arnold, M. Künzli, L. Bordoli, T. Schwede, The SWISS-MODEL Repository and Associated Resources, Nucleic Acids Research, Vol. 37, 2009, pp. D387-D392. 